\title{
Globe
}

Revue internationale d'études québécoises

\section{Ursula Mathis-Moser : Dany Laferrière.La dérive américaine. Montréal, VLB éditeur, 2003}

\section{Najib Redouane}

Volume 7, numéro 1, 2004

URI : https://id.erudit.org/iderudit/1000835ar

DOI : https://doi.org/10.7202/1000835ar

Aller au sommaire du numéro

Éditeur(s)

Globe, Revue internationale d'études québécoises

ISSN

1481-5869 (imprimé)

1923-8231 (numérique)

Découvrir la revue

Citer ce compte rendu

Redouane, N. (2004). Compte rendu de [Ursula Mathis-Moser : Dany

Laferrière.La dérive américaine. Montréal, VLB éditeur, 2003]. Globe, 7(1),

203-206. https://doi.org/10.7202/1000835ar d'utilisation que vous pouvez consulter en ligne.

https://apropos.erudit.org/fr/usagers/politique-dutilisation/ 


\section{Recensions}

\section{Ursula Mathis-Moser}

Dany Laferrière. La dérive américaine.

Montréal, VLB éditeur, 2003.

Auteur d'une cuvre substantielle, à la fois lucide et délirante, Dany Laferrière, né en 1953 à Port-au-Prince, a plus que tout autre écrivain haïtien été reconnu au Québec, où son œuvre est largement médiatisée, depuis la publication en 1985 de son premier roman Comment faire l'amour avec un nègre sans se fatiguer? Ce roman a d'ailleurs connu un succès international et a été adapté au cinéma. Le dixième roman de Laferrière, Le Cri des oiseaux fous (2000), vient clore ce qu'il a lui-même appelé le cycle de son "autobiographie américaine".

C'est de l'Autriche, plus précisément d'Innsbruck, que nous vient le premier ouvrage qui souligne l'importance quantitative et qualitative de l'œuvre de Laferrière. Ursula Mathis-Moser, professeure de philologie romane et directrice du Centre d'études canadiennes et du Centre d'études de la chanson québécoise à l'Université d'Innsbruck, retrace l'extraordinaire et déconcertant cheminement de cet écrivain haïtien arrivé au Québec à l'âge de 23 ans pour échapper à la dictature de Duvalier, et qui est devenu une voix importante parmi les écrivains haïtiens de l'exil.

Composé de sept chapitres de longueur inégale, Dany Laferrière. La dérive américaine est incontestablement un essai qui, à partir du thème général de la dérive, propose une analyse exigeante et minutieuse de la production romanesque de Laferrière, laquelle se distingue dans le champ littéraire haitien par son audace, son originalité et son intensité. Mathis-Moser poursuit un triple objectif : " rendre justice à un écrivain qui n'est plus "un écrivain débutant", mais écrivain "tout court" ; rendre justice à une œuvre qui, avec ses plus de 2200 pages, représente une

Michel Lacroix [éd.], \& Recensions *, Globe. Revue internationale d'études québécoises, vol. 7, $\mathrm{n}^{\circ} 1,2004$. 
fresque gigantesque de l'Amérique de la fin du $\mathrm{xx}^{e}$ siècle ; et décrire cette œuvre à l'aide des instruments élaborés par la critique littéraire " (p. 8).

Afin de mieux comprendre l'itinéraire qu'emprunte l'écriture de Laferrière, Mathis-Moser, dans le premier chapitre intitulé "Essai d'une approche biographique", donne à l'histoire personnelle de Laferrière une place centrale, présente son enfance, ses relations familiales et amicales, ses rapports avec ses parents et son éducation au pays natal, explique le contexte de son exil au Québec et enfin situe sa naissance en tant que romancier à Montréal. En fait, cette ville représente beaucoup pour l'exilé haïtien qui lui restera attaché "comme une patrie intellectuelle, vers laquelle il reviendra régulièrement pour publier ses textes, pour discuter avec son éditeur et pour se mêler de façon pas toujours orthodoxe de la scène littéraire " (p. 30). L'auteure insiste sur l'évolution de l'écrivain depuis son arrivée au Québec jusqu'à son retour à Haïti en 1995, "après presque vingt ans d'absence" (p.13) en passant par son installation à Miami, où il fuit l'hiver en 1990. Laferrière appartient à trois villes, chacune revêtant pour lui une importance considérable : Port-auPrince occupe son cœur, Montréal, sa tête et Miami, son corps.

Comme l'expose le deuxième chapitre "Essai d'une poétique implicite", la raison d'être de l'écriture romanesque de Laferrière est largement liée à son expérience de l'exil. Refusant toute idéologie ou toute appartenance politique, l'écrivain prône la liberté de la plume, élaborant ses trames narratives comme il vit. Ainsi, située entre fiction et réalité, son écriture apparaît comme l'expression manifeste d'un véritable moi, "qui tend à rétablir l'identification entre personnage, narrateur et auteur réel . (p. 53). De plus, l'écriture est marquée par un mouvement qui va de l'espace de la migration pour remonter ensuite vers celui du pays de l'enfance. C'est dans cette perspective que la ville, qu'il s'agisse de Montréal, de Port-au-Prince ou encore de Miami "occupe une place privilégiée dans la topographie laferrienne " (p. 65). Cela dit, la ville en tant que telle lui permet de poser un regard lucide sur le réel, de dénoncer les maux qui rongent son pays natal et de se réserver des espaces de réflexion et d'écriture.

Un troisième chapitre très court dégage les configurations de l'œuvre de Laferrière. À ce niveau, le cadre interprétatif de l'étude met en évidence "la lecture "externe", biographique et poétique, [...] complétée ainsi par une lecture "interne" portant sur plusieurs axes : celui des lieux, 


\section{RECENSIONS}

celui du temps, celui du moi narrateur-personnage et celui de l'architecture du texte * (p. 93). En plus d'expliquer l'essence et l'évolution du concept de la dérive, l'auteure présente un tableau synoptique " qui met en relation la date et le lieu de publication, le lieu présumé de rédaction, le temps (la durée) et les lieux évoqués dans le texte, ainsi que la présence/absence de croisements intertextuels/discursifs "(p. 95).

Respectivement intitulés " Dérive des lieux " et " Dérive du temps ", les quatrième et cinquième chapitres se consacrent à la saisie du concept de la dérive, susceptible de caractériser l'univers littéraire de Laferrière sur le plan poétique et esthétique. Ainsi, la dérive spatiale met en scène "la quête d'un moi dans un monde éclaté ; et l'éclatement croissant de celuici par la suite qui se trame de la petite ville à la métropole " (p. 99). Du Petit-Goâve à Miami, en passant par Port-au-Prince et Montréal, la représentation spatiale revêt de multiples formes discursives qui suggèrent diverses interprétations et les lieux apparaissent tout aussi bien complexes et violents, fascinants et tragiques. Ces variations, ouvertes à toutes sortes d'expériences et d'événements, renforcent le sentiment d'étrangeté, de dérive et de déambulation. Quant à la dérive temporelle, elle fait appel aux stratégies narratives propres à l'écrivain qui élabore la trame de ses récits dans le monde présent, là où il vit, tout en gardant vivace la mémoire de ses origines. Pour Mathis-Moser, les textes de Laferrière se caractérisent tant par une forme de "contemporanéitén que par un recours constant à des attaches temporelles ou affectives au pays de l'enfance. Cette approche mêlant le présent au passé est un "élément essentiel de toute écriture migrante" (p. 143).

Comme les autres écrivains haïtiens qui vivent en exil, Dany Laferrière parle d'Haïti, de la blessure et de la déchirure causées par l'éloignement de sa terre natale, liant ses souvenirs à des émotions individuelles et collectives. Toutefois, l'écrivain réussit à transcender les traces du passé par la réalisation d'une œuvre à caractère résolument autobiographique, mais postmoderne. C'est dans le sixième chapitre, "Promenades frontalières et transgressions ", que l'auteure juge essentiel de dégager certains traits qui révèlent l'originalité et la mouvance des écrits de Laferrière. Situant son analyse dans le cadre de l'hybridité culturelle, elle met en lumière la richesse et la diversité de l'œuvre laferienne en examinant la fragmentation du récit, le mélange des genres, les diverses formes d'intertextualité, de paratextualité et d'intermédialité, ainsi 
que l'architecture du texte et enfin le jeu identitaire, entre autobiographie et autofiction.

, Le dernier chapitre, intitulé "Je suis fatigué *, qui reprend là les mots de l'écrivain, contient une réflexion judicieuse sur le rôle et la place qu'occupe Laferrière dans les champs littéraires haitien et québécois. Il reste que son apport excède ces catégorisations. Laferrière avoue en effet son ambition de n'appartenir qu'à un seul pays, tout en réclamant une certaine universalité.

L'essai de Mathis-Moser est méritoire et contribuera sans doute à faire mieux connaître les subtilités stylistiques et thématiques de la production romanesque de Laferrière. C'est un livre riche en faits divers, témoignages personnels, raccourcis d'actualité, bons mots de journalistes et études pertinentes de critiques qui révèlent l'originalité et la dynamique de l'œuvre d'un écrivain qui n'a cessé de surprendre par son souffle d'écriture simplement autobiograpbique, réussissant bien à démêler le vrai du faux, la réalité de la fiction.

Najib Redouane California State University, Long Beach

\section{Ollivier Hubert}

Sur la terre comme au ciel.

La gestion des rites par l'Église catbolique du Québec (fin $X V 1 I^{e}-m i$-XIX siècle).

Québec, Les Presses de l'Université Laval, 2000.

À toutes les études permettant de mieux analyser la place de l'Église catholique dans la société québécoise il manquait jusqu'ici un chapitre essentiel, celui qui permettait de saisir "la remarquable efficacité et la continuité du dispositif rituel qui fonde finalement (son) hégémonie n (p. 305). Ce chapitre est maintenant magistralement rédigé par Ollivier Hubert. Plusieurs raisons expliquent ce retard, au-delà du silence un peu honteux de toute une génération d'historiens qui ont fait de leur rupture avec l'Église un marqueur identitaire fort. En premier lieu, un tel silence tient sans doute à l'opinion commune selon laquelle le rituel, par sa 